\title{
25. Vapour Pressures of Diethyl Selenide, Tetramethyl Tin and Tetramethyl Lead.
}

By Yoshio TaNaka and Yûzaburô NAGAI. Aeronautical Research Institute, Tokyo Imperial University.

(Comm. by K. Tawara, M.I.A., Feb. 12, 1929.)

The vapour pressures of diethyl selenide, tetramethyl tin and tetramethyl lead were measured by the statical method. The results obtained are shown in Table I.

Table I. Vapour pressures of diethyl selenide, tetramethyl tin and tetramethyl lead ( $\mathrm{mm}$ of mercury column).

\begin{tabular}{c|c|c|c}
\hline Temperature $\left({ }^{\circ} \mathrm{C}\right)$ & Diethyl selenide & Tetramethyl tin & Tetramethyl lead \\
\cline { 2 - 4 } $25 \cdot 0$ & 28 & 112 & 31 \\
35.0 & - & 168 & 51 \\
\hline
\end{tabular}

Now, the vapour pressure $p$ at the absolute temperature $T$ of a substance, which has the boiling point of $T_{B}$ (absolute temperature) and the molecular heat of vaporisation of $L$, is expressed by the equation

$$
\log _{10} p=\log _{10} 760-\frac{L}{2.303 R}\left(\frac{1}{T}-\frac{1}{T_{B}}\right) \ldots \ldots \ldots
$$

Substituting the values for the vapour pressures at $25^{\circ} \mathrm{C}$ shown in Table I into the equation (1), the authors obtained the values for $L / T_{B}$ and $L / R$ of three substances above mentioned, as shown in Table II.

Table II. $L / R$ and $L / T_{B}$ of diethyl selenide, tetramethyl tin and tetramethyl lead.

\begin{tabular}{c|c|c|c}
\hline & Diethyl selenide & Tetramethyl tin & Tet:amethyl lead \\
\hline$T_{B}$ & 383 & 350.5 & 383 \\
$L / R$ & $4.43 \times 10^{3}$ & $3.811 \times 10^{3}$ & $4.30 \times 10^{3}$ \\
$L / T_{B}$ & 22.9 & 21.6 & 22.3 \\
$9.5 \log _{10} T_{B}-0.007 T_{n}$ & 21.9 & 21.7 & 21.9 \\
\hline
\end{tabular}


It is very interesting to see that the values for $L / T_{B}$ coinside closely with those calculated on the basis of the revised rule of Trouton, showing that diethyl selenide, tetramethyl tin and tetramethyl lead are all the normal liquids.

Substituting the values for $L / R$ shown in the Table II into the equation (1), the authors obtained the following equations, which give the vapour pressures $p$ (mm of mercury column) of three substances above mentioned at any reasonable temperature $T$.

$$
\begin{aligned}
& \log _{10} p=7.905-\frac{1924}{T} \text { (For diethyl selenide) } \\
& \log _{10} p=7.602-\frac{1655}{T} \text { (For tetramethyl tin) } \\
& \log _{10} p=7.751-\frac{1865}{T} \text { (For tetramethyl lead) }
\end{aligned}
$$

Calculating the vapour pressures at $35.0^{\circ} \mathrm{C}$ of tetramethyl tin and tetramethyl lead on the basis of the above formula, the authors obtained the values of $169 \mathrm{~mm}$ and $50 \mathrm{~mm}$, respectively, which are concordant with the value obtained by the experiment. 